I have misunderstood the notice, because I did not remain in the UK for senior registrar and consultant posts, the College has agreed to deem me "untrained" for the purpose of the Register.

What limitations will that place on my future employment in the UK (and Europe)?

I have been a Member of the College since 1973. An outline of the benefits of continuing membership would also be timely.

20 Staniland Avenue

ANDREW FIRESTONE

Malvern, Victoria 3144

Australia

\title{
Molecular genetic study of familial presenile dementias
}

DeAr Sirs

We have been funded by the Medical Research Council to carry out a molecular genetic study of Familial Alzheimer's disease. This has concentrated on demonstrating linkage with markers on the proximal long arm of chromosome 21 . We have recently had our funding extended and this now includes molecular genetic studies of other familial presenile dementias, excluding Huntington's disease. We would be most interested to learn from colleagues of any families with presenile dementia. The study will involve the collection of blood samples from both affected and unaffected members and a brief clinical assessment. If you are in contact with any families that might wish to assist with our research we would be grateful if you could contact Dr M. N. Rossor at the address below.

Alzheimer's Disease Research Group

M. N. Rossor

Department of Neurology

St Mary's Hospital

Praed Street, London W2 INY

Alzheimer's Disease Research Group

Department of Biochemistry

St Mary's Hospital Medical School

Praed Street, London W2 INY

\section{Myolink and computer enhanced bio-feedback}

DeAR SIRS

I wonder if any of your readers can help come up with a programme for the use of the Myolink and Relaxometer with a BBC computer to enhance relaxation. We have this equipment but the programmes enclosed from the manufacturer are not adequate for our purposes.

I look forward to hearing from anyone with a similar problem, or better still, with a solution!

St Canice's Psychiatric Hospital

Niall GriffiN

Kilkenny, Ireland

\section{Video news and education service}

\section{DeAr SirS}

I am pleased to report that this experiment is under way and a tape has been sent to all clinical tutors. If anyone would like to view this tape I would ask them to contact their clinical tutor in the first instance. Additional copies are available and anyone interested in this project is welcome to contact me at the address below.

Department of Psychiatry

A. Macaulay

Wexham Park Hospital

Slough, Berkshire SL2 4HL 